\title{
SIMULATING THE TECHNOLOGICAL MOVEMENTS OF THE EQUIPMENT USED FOR MANUFACTURING PROSTHETIC DEVICES USING 3D MODELS
}

\author{
CHICEA Anca-Lucia \\ (Lecturer, / Ph.D. ), Faculty of Engineering/Department of Industrial Machines and Equipment, "Lucian \\ Blga" University of Sibiu, Sibiu, Romania, anca.chicea@ulbsibiu.ro
}

\begin{abstract}
The paper presents the process of building geometric and kinematic models of a technological equipment used in the process of manufacturing devices. First, the process of building the model for a six axes industrial robot is presented. In the second part of the paper, the process of building the model for a five-axis CNC milling machining center is also shown. Both models can be used for accurate cutting processes simulation of complex parts, such as prosthetic devices.
\end{abstract}

Key words: industrial robot, CNC milling machine, kinematic models

\section{Introduction}

The main stages of manufacturing prosthetic devices using computer assisted techniques are [14]:

- Determination of the shape of the product either from the human subject by means of computerized tomography or from an existing model of it by means of 3D scanning;

- Data transfer to a CAD system for prosthetic design and engineering analysis (CAE);

- Rapid prototyping for design examination and surgery planning;

- Manufacturing the device in a CAM system using CNC machine tools.

Once a computer-aided design (CAD) model has been produced, it can be adjusted digitally to facilitate attachment of the prosthesis, [5-7].

Depending on the geometric complexity and biomaterial chosen, one or more manufacturing processes can be selected. In some cases, more than one manufacturing process is usually required to produce the implant.

Two of the most used technological processes for manufacturing prosthetic device are milling and incremental forming [8], [9]. Both processes can be unfolded using either CNC milling machines or serial industrial robots as technological equipment (fig. 1). 

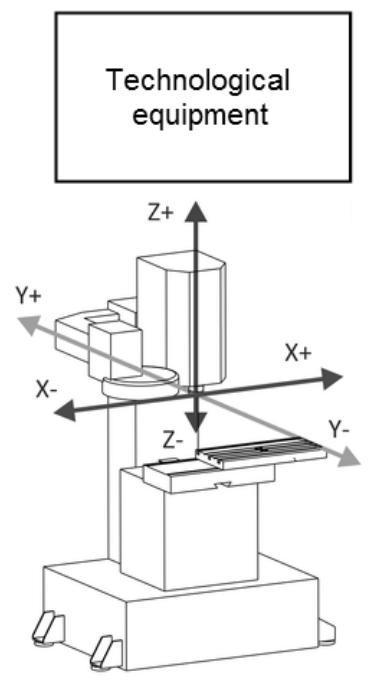

CNC milling machine
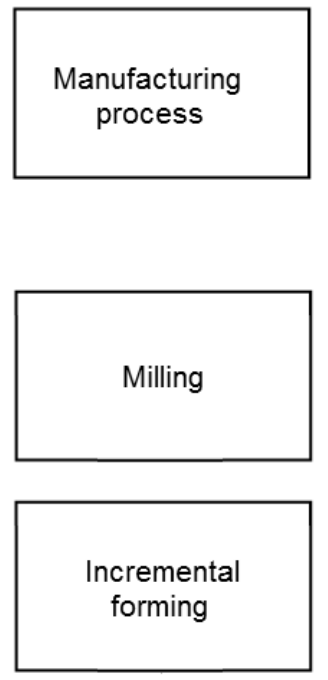

forming

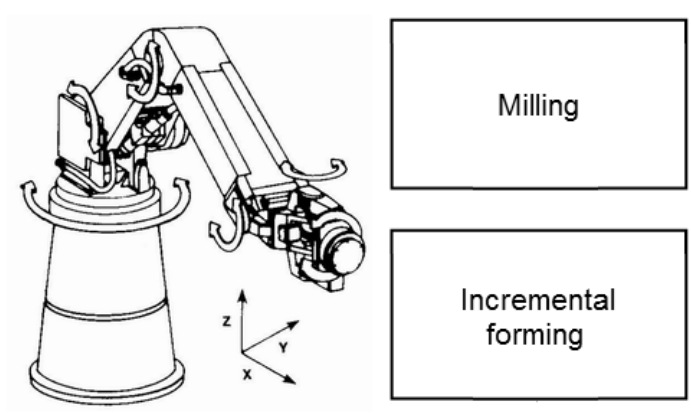

Industrial robot

Figure 1: Technological equipment and manufacturing processes for used for manufacturing prosthetic devices

In order to simulate the technological movements during the manufacturing process, geometric and kinematic models for the technological equipment have to be build.

\section{The 3D kinematic model of the KUKA KR 6-2 robot}

This approach was targeted to use the serial industrial robot KUKA KR 6-2, which is available in the laboratories of "Lucian Blaga" University of Sibiu, for milling complex parts, such as prosthetic devices. For generating the toolpaths and the program for controlling the robot, the SprutCAM software package was used [10].

The CAM program is able to control the paths of the end-effecter of the robot, also keeping the robotic structure outside singularity points. However, it is also require checking the collisions between the mobile elements of the robotic structure. In order to do that, the user has to build a 3D kinematic model of the robotic structure, according to the following steps:

- building the 3D geometric model of the robot and saving it as .igs file (usually, the manufacturer of the robot provides this model. The 3D model used in this work was downloaded from the KUKA website)

- dividing the 3D geometric model into the main moving components of the robotic structure (together with the robot frame, which is a fixed);

- opening each component into SprutCAM workspace and saving it in .osd format;

- creating a .xml file which defines the kinematic and geometry of the robotic structure (SprutCAM provides a template .xml file, which can be modified by the user.

In figure 2, the overall 3D geometric model of the KUKA KR 6-2 robot is presented, together with the main moving components (modules) are presented. The main components are the robot frame and the rotational axes, from Axis A1 to Axis A6. 

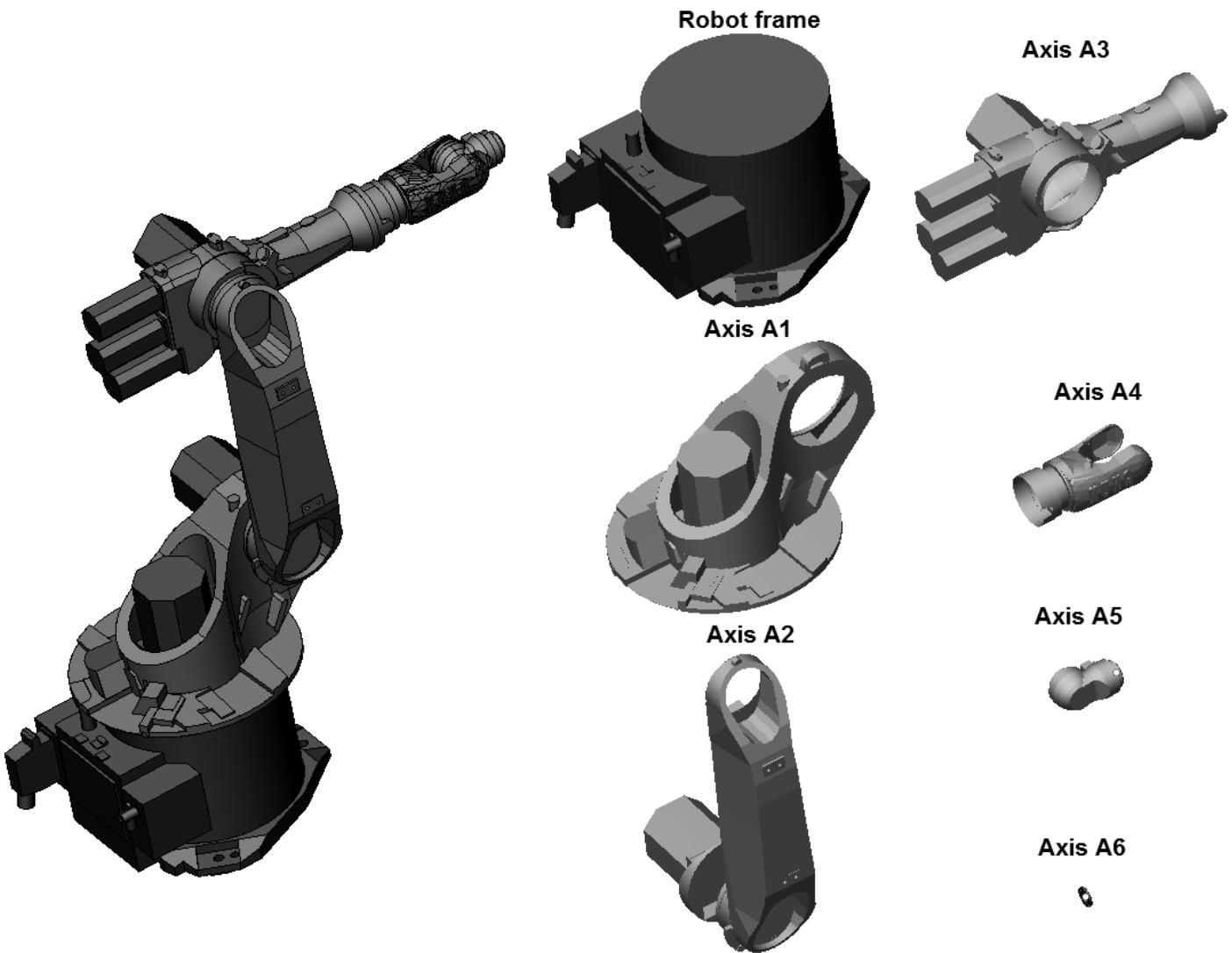

Axis A5

Axis A6

8

Figure 2: The 3D geometric model and the main modules

In order to edit the .xml file, the dimensions presented in figure 3 have to be measured on the robot and introduced within the file.

Aside from the characteristic dimensions from figure 2, the .xml file should also include the angular limits for each rotational axis.

The dimensions from figure 3, together with the angular limits for axis A2 and A3 are presented in figure 4, provided by the KUKA KR 6-2 operating manual.

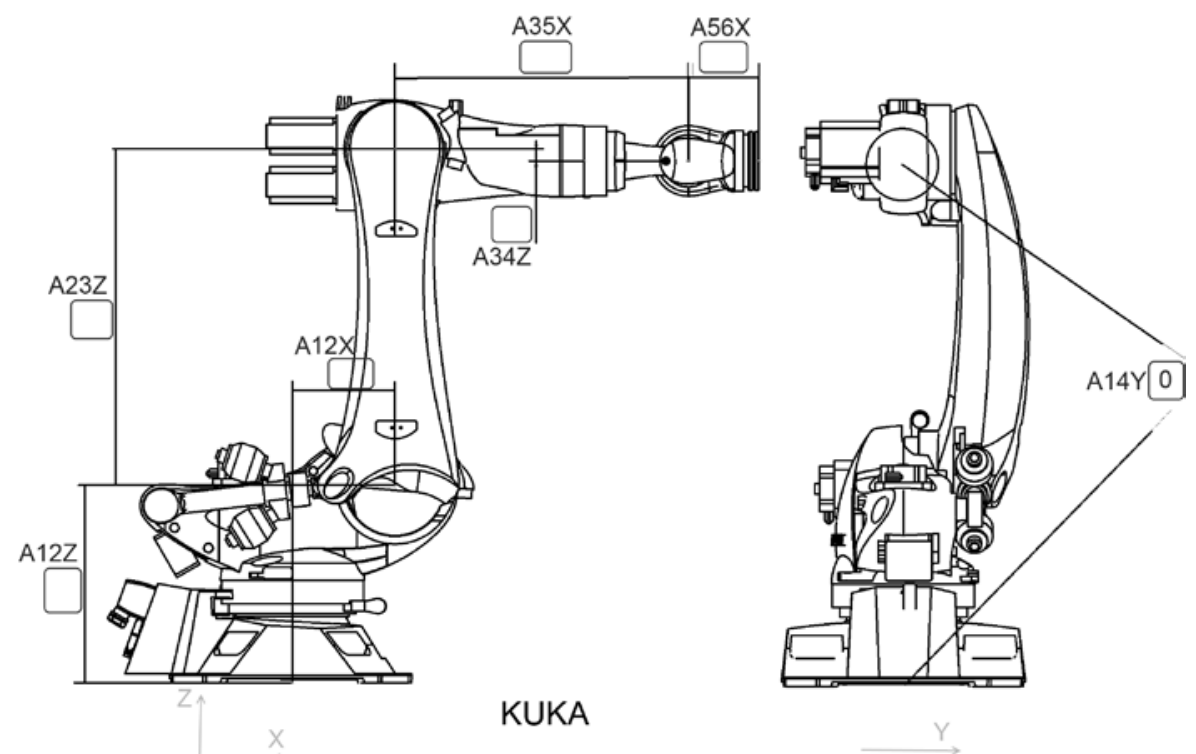

Figure 3: The characteristic dimension of the robot which have to be introduced in the .xml file 


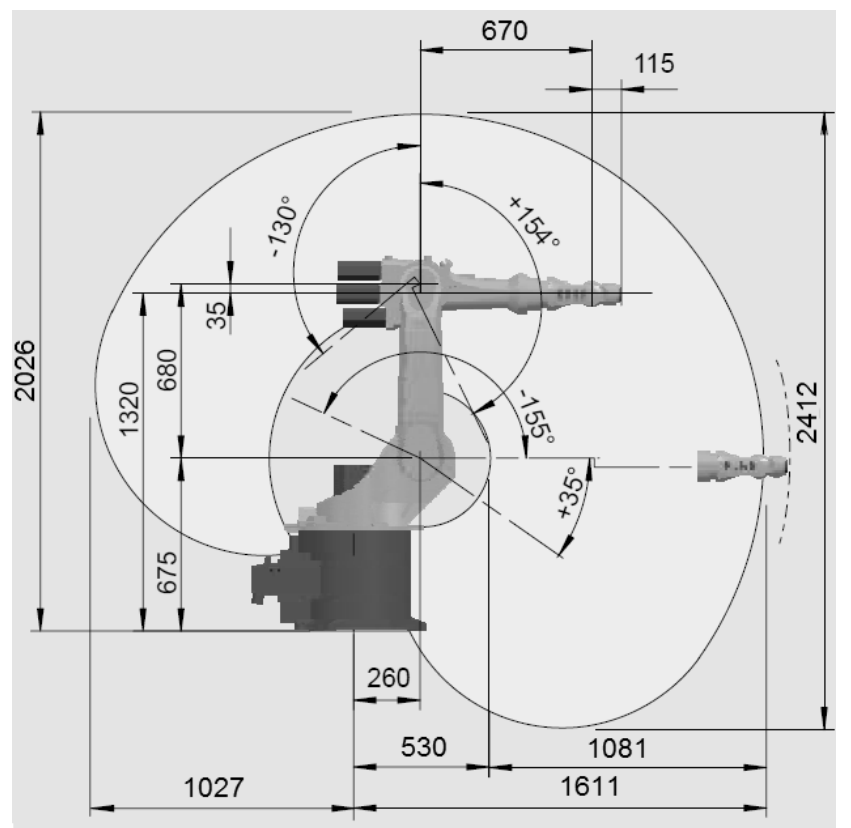

Figure 4: The numerical values of the required dimensions (linear and angular)

In order to use the KUKA KR 6 robot for milling processes, a milling unit, as robot end-effecter had to be designed.

The main requirements for the milling unit were:

- high achievable speeds;

- continuous speed control over a wide range of values;

- easy coupling between the milling unit and the robot structure (at axis A6 level);

- reduced overall dimensions and weights while still having a reasonable rigidity in order to be able to manufacture parts by means of milling (the maximum weight which can be manipulated by the KUKA KR 6-2 robot is $6 \mathrm{~kg}$ ).

In order to fulfill these requirements, a PROXXON MICROMOT 50/EF milling/drilling machine was used as working unit, together with a PROXXON MICROMOT NG 2/E voltage transformer.

The system composed from the above mentioned units allow a continuous speed control between $5000-20000 \mathrm{rpm}$ and has an overall weight under $2 \mathrm{~kg}$. Also, due the reduced working voltages (between 12-18 V), the systems allows the use of coolants. The overall power requirement for the milling unit is $40 \mathrm{~W}$.

Finally, the model of the robot during a milling process is presented in figure 5.

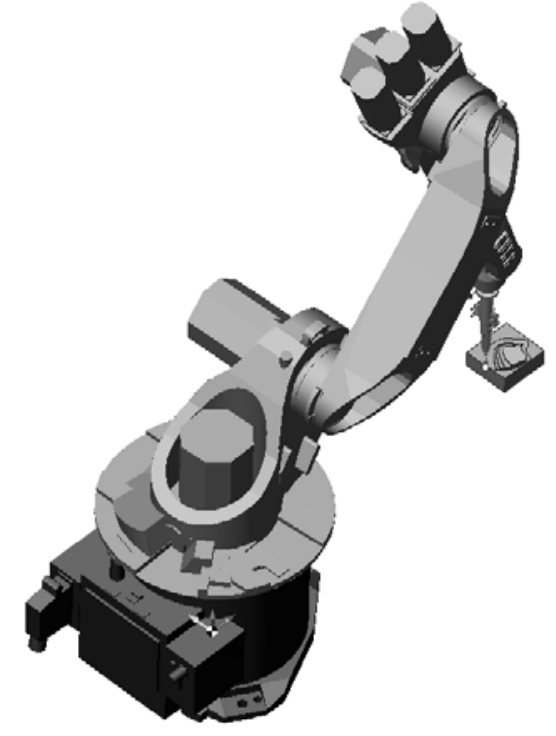

Figure 5: Milling using an industrial robot

\section{The Geometric and Kinematic Model of the Five-axis Machining Center}


The second part of the researches presented in this paper were oriented to build the kinematic model of a five-axis vertical machining center built presented in figure 6 .

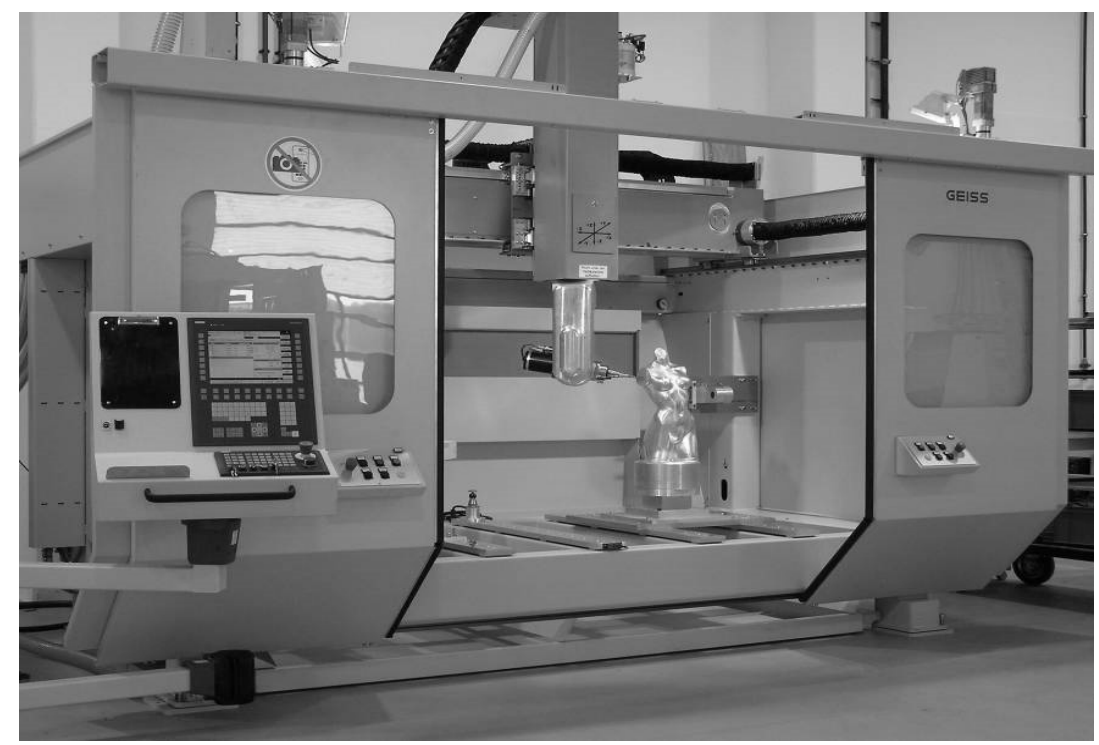

Figure 6: The five axis machining center

The first step involves the build of the 3D model of the machine tools as a 3D assembly, using a general purpose CAD program. The 3D model of the five axis machining center is presented in figure 7 a). Figure $7 \mathrm{~b}$ ) shows an enlarged view of the machining head (rotational axes B and C).

After completing the first step, the next one involves the export of each component of the assembly as an igs file. This second step is also performed using the CAD program.

The third step is based on the import of the igs files in the CAM software package core program followed by their export in osd format.

The fourth step, which is the most important one, is performed in in a special external module of the CAM software package and is based on the reconstruction of the machine model from the osd files, while defining the kinematic of the machine.

For each mobile element of the machine, the user has to define the axes along (for translational axes) or around (for rotational axes) the element is moving. Moreover, the user has to define the limits of the movements for each element.

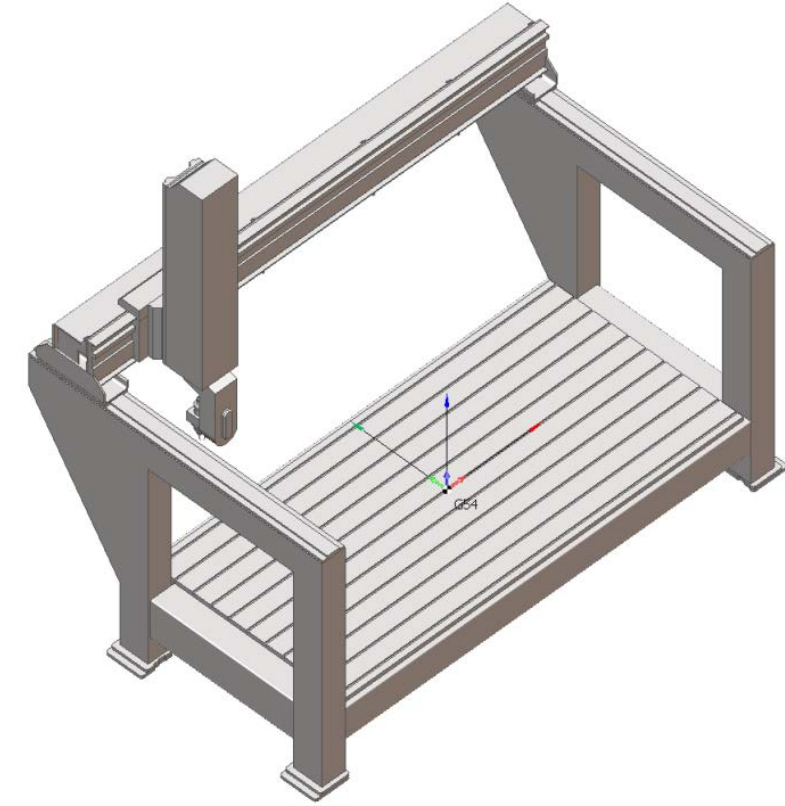

a

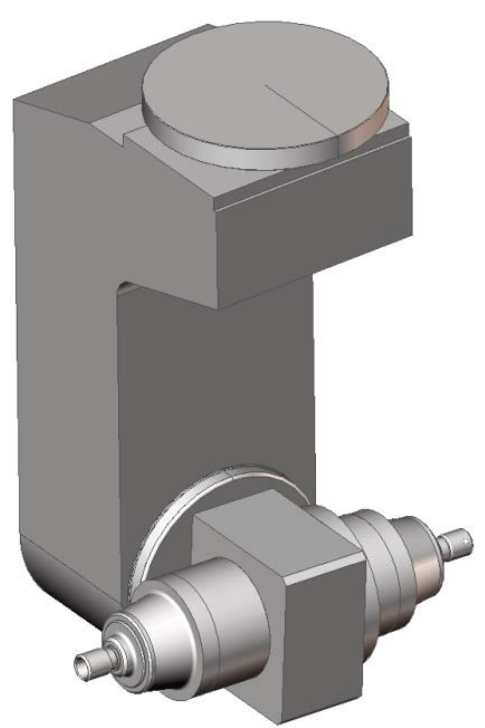

b

Figure 7: a) The 3D model of the five axes machining center; $b$ ) The machining head

The flowchart of building geometric and kinematic models for multi-axes CNC machine tools, used within this research is presented in figure 8. 


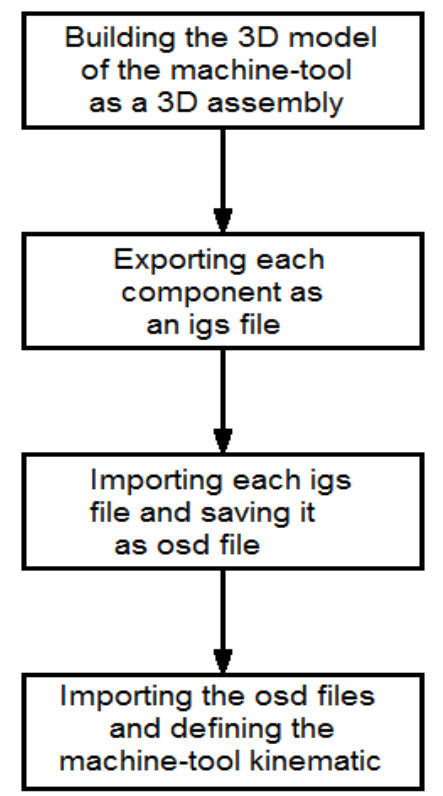

Figure 8: The flowchart of building geometric and kinematic models for multi-axes CNC machine tools

\section{Conclusions}

In order to simulate a multi-axes machining process, mainly milling, a geometric and kinematic model of the industrial robot and/or of the CNC machine-tool is required. Some of the CAM software packages include libraries of such models, but for the newest models of industrial robots and/or CNC machine-tool cannot be included.

Consequently, the user has to be able to build such models, using specific tools, provided with the CAM software, either as internal or external modules.

This paper presented the process of building the geometric and kinematic model of both a serial industrial robot and a five-axis machining center,

\section{Acknowledgment}

This work was supported by the strategic grant POSDRU/159/1.5/S/133255, Project ID 133255 (2014), co-financed by the European Social Fund within the Sectorial Operational Program Human Resources Development 2007 -2013.

\section{References}

1. A. Werner, Z. Lechniak, K., Skalski, K. Gdzior, Design and Manufacture of anatomical hip joint endoprostheses using CADCAM system, Journal of Materials Processing Technology, 107, 1, (2000), 81-186.

2. M. Dietrich, K. Gdzior, K. Skalski, Design and manufacturing of the human bone endoprostheses using computer-aided system, Journal of Theoretical and Applied Mechanics, Vol.37, 3, (1999) 481-503.

3. A.R. Fathi, S. Marbacher, A. Lukes, Cost-effective patient-specific intraoperative molded cranioplasty, J. Craniofac. Surg. 19 (3), (2008), 777-781;

4. W. Smolik, P. Brzeski, K. Gdzior, K Skalski, R. Szabatin, W. Mwigszkowski, Tomographic image processing for geometrical modeling in CAD system. Proc. of Tenth World Congress on the Theory of Machines and Mechanisms, Oulu, Finland, Vol.5, (1999) 1871-1876.

5. J. Vander Sloten (ed.), Computer Technology in Biomaterials Science and Engineering, John Wiley and Sons Ltd, (2000).

6. T. Varady, R. Martin, J. Cox, Reverse engineering of geometric models: an introduction, Computer-Aided Design 29 (4) (1997) 255-268.

7. S. Singare, L. Yaxiong, L. Dichen, L. Bingheng, H. Sanhu and L. Gang, Fabrication of Customised MaxilloFacial Prosthesis Using Computer-Aided Design and Rapid Prototyping Techniques, Rapid Prototyping Journal 12 (2006) 206-213.

8. E. Budak, E. Ozturk, L.T. Tunc, Modeling and simulation of 5-axis milling processes, CIRP Annals Manufacturing Technology, Volume 58, Issue 1, (2009), pp. 347-350.

9. G. Ambrogio, L. De Napoli, L. Filice, F. Gagliardi, M., Muzzupappa, Application of Incremental Forming process for high customised medical product manufacturing, Journal of Materials Processing Technology 162163 (2005) 156-162;

10. ***, SprutCAM version 9 user guide, Sprut Technolgy JSC, http://www.sprutcam.com, (2015). 